\title{
Short Hairpin RNA against PTEN Enhances Regenerative Growth of Corticospinal Tract Axons after Spinal Cord Injury
}

\author{
Katherine Zukor, ${ }^{1}$ Stephane Belin, ${ }^{1}$ Chen Wang, ${ }^{1}$ Nadia Keelan, ${ }^{1,2}$ Xuhua Wang, ${ }^{1}$ and Zhigang He ${ }^{1}$ \\ ${ }^{1}$ F. M. Kirby Program in Neuroscience, Children's Hospital Boston, Harvard Medical School, Boston, Massachusetts 02115, and ${ }^{2}$ Smurfit Institute of \\ Genetics, Trinity College, Dublin 2, Ireland
}

Developing approaches to promote the regeneration of descending supraspinal axons represents an ideal strategy for rebuilding neuronal circuits to improve functional recovery after spinal cord injury (SCI). Our previous studies demonstrated that genetic deletion of phosphatase and tensin homolog (PTEN) in mouse corticospinal neurons reactivates their regenerative capacity, resulting in significant regeneration of corticospinal tract (CST) axons after SCI. However, it is unknown whether nongenetic methods of suppressing PTEN have similar effects and how regenerating axons interact with the extrinsic environment. Herein, we show that suppressing PTEN expression with short-hairpin RNA (shRNA) promotes the regeneration of injured CST axons, and these axons form anatomical synapses in appropriate areas of the cord caudal to the lesion. Importantly, this model of increased CST regrowth enables the analysis of extrinsic regulators of CST regeneration in vivo. We find that regenerating axons avoid dense clusters of fibroblasts and macrophages in the lesion, suggesting that these cell types might be key inhibitors of axon regeneration. Furthermore, most regenerating axons cross the lesion in association with astrocytes, indicating that these cells might be important for providing a permissive bridge for axon regeneration. Lineage analysis reveals that these bridge-forming astrocytes are not derived from ependymal stem cells within the spinal cord, suggesting that they are more likely derived from a subset of mature astrocytes. Overall, this study reveals insights into the critical extrinsic and intrinsic regulators of axon regeneration and establishes shRNA as a viable means to manipulate these regulators and translate findings into other mammalian models.

\section{Introduction}

It has been proposed that the adult mammalian spinal cord fails to regenerate after injury because mature neurons have a low intrinsic ability to regrow axons and because the environment of the injured spinal cord is inhibitory (Silver and Miller, 2004; Maier and Schwab, 2006; Afshari et al., 2009; Liu et al., 2011). In the past, significant progress has been made in identifying critical intrinsic and extrinsic regulators of axon regeneration. However, there is no efficient combinatorial neural repair strategy that deals with both extrinsic and intrinsic factors.

Recently, studies have revealed several molecular pathways that regulate intrinsic growth, such as cAMP (Qiu et al., 2002), SOCS3/STAT3 (Smith et al., 2009; Sun et al., 2011), DLK (Hammarlund et al., 2009; Yan et al., 2009; Shin et al., 2012; Watkins et al., 2013), PTEN/mTOR (Park et al., 2008; Kurimoto et al., 2010; Liu et al., 2010), and KLFs (Moore et al., 2009; Blackmore et al.,

Received June 13, 2013; revised Aug. 11, 2013; accepted Aug. 13, 2013.

Author contributions: K.Z. and Z.H. designed research; K.Z., S.B., C.W., and X.W. performed research; K.Z. and N.K. analyzed data; K.Z., S.B., and Z.H. wrote the paper.

This work was supported by the National Institutes of Health, Dr. Miriam and Sheldon G. Adelson Medical Research Foundation, Unite 2 Fight Paralysis, Travis Roy Foundation and Massachusetts Walks Again, Empire Hotel, and Cure Medical. K.Z. was supported by the Craig H. Neilsen Foundation. S.B. was supported by the William Randolph Hearst Fund. We thank Jonas Frisen for Nestin-CreERT mice, Siwei Li for technical support, and Kyle Costa for help with mouse care.

The authors declare no competing financial interests.

Correspondence should be addressed to Dr. Zhigang He, Children's Hospital Boston, 3 Blackfan Circle, CLS 13060, Boston, MA 02115. E-mail: zhigang.he@childrens.harvard.edu.

DOI:10.1523/JNEUROSCI.2510-13.2013

Copyright $\odot 2013$ the authors $\quad 0270-6474 / 13 / 3315350-12 \$ 15.00 / 0$
2012). Of these, phosphatase and tensin homolog (PTEN) deletion (Liu et al., 2010) has been shown to promote the regenerative growth, as opposed to sprouting growth, of descending, supraspinal axons in adult mammals. Specifically, we found that genetic deletion of PTEN dramatically enhances the intrinsic growth of adult mouse corticospinal tract (CST) neurons such that they are able to regenerate numerous axons beyond a spinal cord lesion (Liu et al., 2010). It is unknown, however, whether PTEN levels can be sufficiently decreased via nongenetic methods to yield similar effects. Such nongenetic methods will allow translation of findings into other mammalian systems as well as provide more flexibility for combining therapies addressing both intrinsic and extrinsic factors limiting regeneration.

In vitro studies have identified many extrinsic components of the injured spinal cord as either permissive or inhibitory for neurite outgrowth. The in vivo role of many of these factors, however, is unclear (Condic and Lemons, 2002; Yiu and He, 2006; Lee and Zheng, 2012). Indeed, the power of in vivo studies to reveal the true role of extrinsic factors is severely limited by the fact that axons regenerate so poorly in the adult central nervous system (CNS). This issue has been circumvented by a few studies, wherein sensory neurons were made to be growth-competent by a preconditioning lesion or extracted and seeded into the spinal cord (Davies et al., 1999, 2006). Although these approaches have been fruitful, it would be desirable to have an in vivo model in which endogenous supraspinal descending axons possess an intrinsic regrowth capacity so that the permissive and inhibitory nature of cells and molecules in the injured CNS environment can be analyzed. 
In this study, we show that short-hairpin RNA (shRNA) against PTEN, similar to gene deletion, can be used to sufficiently knock down PTEN and enhance the intrinsic growth of CST axons after a crush spinal cord injury (SCI). Indeed, many CST axons are able to regenerate across the lesion and make synapses caudal to the injury. Taking advantage of this model of enhanced intrinsic growth, we analyzed what extrinsic factors appear to support or inhibit regeneration. We show that axons grow across the lesion in close association with astrocyte bridges but avoid dense clusters of fibroblasts and macrophages. Moreover, axons that do not cross the lesion stop at the sharp border formed by fibroblasts and astrocytes at the lesion's edge. With this shRNA tool, we now have more flexibility to test hypotheses regarding the true role of these cell types on axon regeneration in not only the mouse, but also other mammalian models.

\section{Materials and Methods}

shRNA and adeno-associated virus (AAV) preparation. The shRNA targeting sequence against mouse PTEN mRNA (shPTEN) was previously validated and used to effectively knock down PTEN in the mouse brain in vivo (Xin et al., 2005; Luikart et al., 2011). The targeting sequence is AGGTGAAGATATATTCCTCCAA, and the hairpin sequence is TCAAGAG.

The expression plasmid for AAV preparation was pAAV-MCS (Stratagene) with green fluorescent protein (GFP) inserted into the multiple cloning site downstream of the CMV promoter. To accommodate shRNA expression, the U6 shRNA expression section from pRS (Origene) was cloned between the ITR and CMV promoter of pAAVMCS, and the shPTEN construct was inserted between HindIII and BamHI sites downstream of the U6 promoter. The control expression plasmid had nothing downstream of the U6 promoter.

AAVs, serotype 2, were generated according to previously described methods (Zolotukhin et al., 1999; Grieger et al., 2006). Briefly, HEK293T cells were cotransfected with the three plasmids of the AAV Helper-Free system (pAAV-shPTEN-GFP, pAAV-RC2, pAAV-helper) in a 1:1:1 molar ratio. Cells were collected $3 \mathrm{~d}$ later, and cell nuclei were extracted and lysed with high-salt buffer and sonicated. After pelleting cellular debris and clearance of DNA/RNA, AAVs were separated from the lysate using a discontinuous iodixanol gradient and filtered and concentrated using Millipore Amicon Ultra filter units (UFC910008; 100,000 MWCO). AAVs were then aliquoted and stored at $-80^{\circ} \mathrm{C}$.

Functional titers were determined using thawed aliquots by transducing HEK293T cells with virus for $3 \mathrm{~d}$ and estimating the number of GFP-positive cells in wells containing serial dilutions of virus. Titers were estimated to be between 0.5 and $1 \times 10^{11} \mathrm{ifu} / \mathrm{ml}$.

Western blot. HEK293T cells were infected with AAV-shPTEN-GFP or AAV-GFP for $3 \mathrm{~d}$. Cells were then collected and lysed in Laemmli buffer. A total of $20 \mu \mathrm{g}$ of protein was resolved by $4-12 \%$ SDS-PAGE (Invitrogen) and transferred onto PVDF membranes (Immobilon-P; Millipore). The membranes were incubated with antibodies against phospho-S6 (Cell Signaling Technology), PTEN (Cell Signaling Technology), or tubulin (Covance) at $1 / 1000$ dilution. Proteins were revealed by chemiluminescence (ECL from GE Healthcare) using the appropriate peroxidase-conjugated secondary antibodies (Jackson ImmunoResearch Laboratories) diluted 1/10,000. Exposed films were imaged on a Typhoon PhosphorImager (GE Healthcare), and the integrated density of each band was quantified in ImageJ (Schneider et al., 2012). Values were normalized to the integrated density of the tubulin bands.

Mice and surgeries. All experimental procedures were performed in compliance with animal protocols approved by the Institutional Animal Care and Use Committee at Boston Children's Hospital. Pregnant wildtype C57BL6 female mice were ordered from Charles River. Newborn pups (P1/P0) were cryoanesthetized for 4 min for AAV injection and were revived on a warming pad until they regained normal color and activity and then returned to their mothers. Sexually mature mice (6-8.5 weeks old) were anesthetized with ketamine/xylazine, their eyes were protected with aqua-tears, and surgical sites were shaved and cleansed with betadine and 70\% ethanol before surgery. Mice were placed on a warming pad after surgery until fully awake and given buprenorphine for pain relief ( 2 times per day for $3 \mathrm{~d}$ after SCI surgery, 2 times per day for $2 \mathrm{~d}$ after brain injection). Their bladders were manually expressed 2 times per day for the duration of the experiments. Female mice were used for most experiments, except for those that were terminated $1 \mathrm{~d}$ after SCI.

$A A V$ injection. Newborn pups were injected with $\mathrm{AAV}$ at $\mathrm{P} 0 / \mathrm{P} 1$ as described previously (Liu et al., 2010). Briefly, cryoanesthetized pups were injected with three injections of $500 \mathrm{nl}$ of AAV-shPTEN-GFP or AAV-GFP into the right sensorimotor cortex using a glass pipette attached to a nanoliter injector that was controlled by the microsys 4 controller (WPI). Fast green $(0.5 \mathrm{mg} / \mathrm{ml}$ stock) was added to the virus at $\sim 1 / 20$ dilution to tint the solution, and the virus was injected at a rate of $800 \mathrm{nl} / \mathrm{min}$.

Spinal cord injury. A full crush injury was performed at thoracic level 8 (T8) similar to that described by Liu et al. (2010). A midline incision was made over the thoracic vertebrae. The fat and muscle were cleared from T8 and T9. While holding onto T9 with forceps, a laminectomy was performed at T8 until the spinal cord was exposed completely from side-to-side. The spinal cord was then fully crushed for $2 \mathrm{~s}$ with forceps that had been filed to a width of $0.1 \mathrm{~mm}$ for the last $5 \mathrm{~mm}$ of the tips. Care was taken to insert the tips on either side of the cord to include the full width of the cord and then to gently scrape them across the bone on the ventral side to not spare any tissue ventrally or laterally. For some animals, wider forceps were used $(0.5 \mathrm{~mm})$. The muscle was sutured, and the skin was closed with wound clips.

Axon tracer injection. Mice were placed on a stereotaxic frame, and a midline incision was made over the skull to reveal bregma. A window in the skull was made with a microdrill and a $0.5 \mathrm{~mm}$ bit to expose the sensorimotor cortex, and the axon tracer, biotinylated dextran amine (BDA, 10\% solution in water, Invitrogen, D1956) tinted with fast green $(1 / 20$ of $0.5 \mathrm{mg} / \mathrm{ml}$ stock), was injected into the cortex through a glass pipette attached to a nanoliter injector. Four injections of $500 \mathrm{nl}$ were injected at a rate of $50 \mathrm{nl} / \mathrm{min}$. The coordinates were as follows: $1.5 \mathrm{~mm}$ lateral, $0.6 \mathrm{~mm}$ deep, and $0.5 \mathrm{~mm}$ anterior; $0.0 \mathrm{~mm}, 0.5 \mathrm{~mm}$, and $1.0 \mathrm{~mm}$ caudal to bregma. The needle was left in place for $1 \mathrm{~min}$ before moving to the next site. The brain was kept moist during the procedure by moving the skin over the exposed area after each injection. The skin was closed with sutures.

Perfusion and tissue collection. Mice were given a lethal dose of anesthesia and transcardially perfused with PBS followed by $4 \%$ paraformaldehyde. Brains and spinal columns were isolated and postfixed in the same fixative overnight, rocking at $4^{\circ} \mathrm{C}$. Tissues were rinsed twice in PBS and dissected further. The spinal cord was dissected out of the spinal column and cut into an $8 \mathrm{~mm}$ segment containing the lesion site $(3 \mathrm{~mm}$ rostral and $5 \mathrm{~mm}$ caudal to the lesion). Approximately $2 \mathrm{~mm}$ segments above and below this were kept to analyze cross sections above and below the lesion. The right side of the brain and the entire brainstem were also isolated. Tissues were cryoprotected in $30 \%$ sucrose in PBS for $3 \mathrm{~d}$ at $4^{\circ} \mathrm{C}$ and then embedded in OCT (Tissue-Tek), frozen in a dry ice/ethanol bath, and stored at $-20^{\circ} \mathrm{C}$. The right side of the brain and SCI sites were embedded for sagittal sections, and the brainstem and rostral and caudal segments of spinal cord were embedded for cross sections.

Immunohistochemistry. Sections were cut on a cryostat at 25-30 $\mu \mathrm{m}$ thick and stored at $-20^{\circ} \mathrm{C}$ until processed. Before staining, sections were warmed to room temperature and dried on a $37^{\circ} \mathrm{C}$ slide warmer for $\sim 2 \mathrm{~h}$. Sections were encircled with a hydrophobic barrier, rinsed once with PBS, and blocked for $1 \mathrm{~h}$ with $10 \%$ normal serum, $1 \%$ Triton X-100 in PBS. All antibodies were diluted in $10 \%$ normal serum in PBS. Primary antibodies and dilutions used are listed in Table 1. Secondary antibodies conjugated to Alexa-488, Cy3, Cy5, Alexa-647, or Alexa-405 were from Invitrogen or Jackson ImmunoResearch Laboratories and diluted 1/200. Sections were incubated with primary antibody overnight at $4^{\circ} \mathrm{C}$, rinsed three times in PBS, incubated with secondary antibody for $2 \mathrm{~h}$ at room temperature, rinsed three times in PBS, incubated with Hoechst 33342 (Invitrogen, 1/2000 in PBS), and rinsed twice in PBS. Coverslips were mounted with Fluoromount G (Southern Biotechnology). For BDA labeling, endogenous peroxidases were quenched with $0.3 \% \mathrm{H}_{2} \mathrm{O}_{2}$ in PBS for $30 \mathrm{~min}$ and rinsed twice with PBS before blocking. Streptavidin-HRP 
Table 1. Primary antibodies ${ }^{a}$

\begin{tabular}{llll}
\hline Antibody & Antibody type & Company, catalog no. & Dilution \\
\hline Phospho-S6 & Rabbit pAb & Cell Signaling Technology, 4857 & $1 / 200$ \\
PTEN & Rabbit mAb & Cell Signaling Technology, 9188 & $1 / 100$ \\
NeuN & Mouse mAb & Millipore, clone A60 & $1 / 200$ \\
GFP & Chick pAb & Abcam 13970 & $1 / 1000$ \\
GFAP & Rabbit pAb & Dako, Z0334 & $1 / 500$ \\
GFAP & Rat lgG2a- $\kappa$ mAb & Invitrogen, 13-0300 & $1 / 1000$ \\
Fibronectin & Rabbit pAb & Chemicon, AB2033 & $1 / 200$ \\
Iba1 & Rabbit pAb & Wako, 019-19741 & $1 / 200$ \\
VGlut1 & Guinea pig pAb & Synaptic Systems, 135 304 & $1 / 500$ \\
PSD95 & Rabbit mAb & Cell Signaling Technology, 3450 & $1 / 100$ \\
MBP & Rat lgG2a mAb & Abcam, ab7349 & $1 / 200$ \\
\hline
\end{tabular}

${ }^{a}$ Summary of primary antibodies and dilutions used. pAb, Polyclonal antibody; mAb, monoclonal antibody; Iba1, ionized calcium binding adaptor molecule 1; VGlut1, vesicular glutamate transporter 1; MBP, myelin basic protein.

(PerkinElmer, NEL750001, 1/300) was added to the secondary antibody solution and incubated with secondary antibodies. After rinsing, sections were incubated with tyramide conjugated to Cy3 (PerkinElmer, SAT704A001, 1/200 in diluent) for $10 \mathrm{~min}$ and rinsed 5 times with PBST (PBS with $0.5 \%$ Triton X-100). For PTEN labeling, antigen retrieval was performed with LAB solution (Polysciences, 24310) for $20 \mathrm{~min}$ at room temperature before blocking.

Quantification of PTEN, phospho-S6, area of cortical neurons. Adjacent sagittal sections of the cortex, perfused $1 \mathrm{~d}$ after SCI, were stained with PTEN or phospho-S6 together with NeuN to label neurons, and GFP to label virus-infected neurons. Sections were imaged at $10 \times$ or $5 \times$ on a Zeis LSM 700 confocal microscope using the same settings for PTEN or pS6 for each section, respectively. Images were cropped to an area of $875.24 \times 250.07 \mu \mathrm{m}^{2}$ for PTEN analysis and $1250.34 \times 357.24 \mu \mathrm{m}^{2}$ for phospho-S6 analysis and analyzed in Image (Schneider et al., 2012). All neurons in each cropped image were outlined based on NeuN staining, and the mean gray value of GFP and PTEN or phospho-S6 staining, as well as the area, was measured for each neuron. Measurements were exported to Excel (Microsoft) and sorted on GFP. Neurons were defined as GFP-positive or GFP-negative if they were in the top or bottom 20-30 neurons per section and they appeared to be GFP-positive or GFPnegative on the image, respectively. Because PTEN knockdown manifested itself as a darker "hole" in the staining compared with a relatively uniform background level, which tended to vary from section to section, PTEN mean gray values were normalized to the background level for each section. There were 3 animals per group, and 3 sections per animal were analyzed. For analysis of PTEN levels, 255 GFP-positive and 293 GFP-negative shPTEN and 234 GFP-positive and 266 GFP-negative control neurons were analyzed. For analysis of phospho-S6 levels, 242 GFPpositive and 270 GFP-negative shPTEN and 251 GFP-positive and 270 GFP-negative control neurons were analyzed.

Quantification of axon regeneration. Sagittal sections through the lesion were stained for BDA and GFAP to identify the lesion edges. Axon regeneration was quantified under $20 \times$ and $40 \times$ objectives on a fluorescent microscope equipped with the Neurolucida system (MBF Bioscience). A grid having lines spaced 0, 100, 500, 1000, 1500, and $2000 \mu \mathrm{m}$ apart was aligned to each section, and the number of axons at each distance from the caudal edge of the lesion was counted. Every fourth, third, or other section through the lesion was quantified for 8, 3-4, and 2 week regenerates, respectively. The total number of axons per animal was then extrapolated by multiplying by the inverse of the fraction of sections quantified. The number of axons at each distance was then normalized to the number of BDA-labeled axons in the brainstem pyramidal tract to control for variations in labeling efficiency.

To obtain this number, the three adjacent cross sections of the brainstem, $1 \mathrm{~mm}$ rostral to the pyramidal tract decussation, were stained for BDA and imaged on a confocal microscope. A $25 \times 25 \mu \mathrm{m}$ grid was placed on each image and cut to the size of the pyramid using the ROI manager in Image (Schneider et al., 2012). The number of labeled axons in every ninth square (of a $3 \times 3$ collection of squares) was counted using stereological counting rules. The area of the entire pyramid and the total area inside the squares that were counted were measured and used to extrapolate the total number of BDA-labeled axons per pyramid.

$3 D$ reconstruction of regenerating axons. Images of every fourth sagittal section through the lesion site of a selection of animals were obtained at $4 \times$ on a spinning disk confocal microscope equipped with a motorized stage to stitch multiple fields of view into an image containing all regenerating axons. Images were aligned in Photoshop (Adobe), arranged in Illustrator (Adobe), locked in place, and then the axons beyond the lesion in each section were traced using a different color for each section. Axons in each section were grouped and aligned into a color-coded $3 \mathrm{D}$ reconstruction.

Lesion analysis and quantification. Images of the lesion site stained for BDA and GFAP were captured at $10 \times$ and stitched on a spinning disk confocal microscope using Volocity software and exported to Image (Schneider et al., 2012) for analysis. The lesion site was defined and traced using GFAP staining as a guide to exclude the main parenchyma of the spinal cord but include $\mathrm{GFAP}^{+}$bridges in the lesion. The RGB image was then split into single channels, and these were thresholded to create selections containing the $\mathrm{BDA}^{+}$and $\mathrm{GFAP}^{+}$regions of the image. The ROI manager was then used to combine regions to obtain regions containing $\mathrm{BDA}^{+}$and $\mathrm{GFAP}^{+}$areas in the lesion, and then regions in the lesion where BDA and GFAP were colocalized. The area inside each of these different regions was measured and exported to Excel (Microsoft). Every sixth or fourth serial section through the lesion was analyzed. Volumes were extrapolated by multiplying the sum of the areas from the serial sections by the section thickness and the inverse of the proportion of sections analyzed.

Lineage analysis of stem cell progeny. Cre-mediated recombination in Nestin-CreERT Rosa-lox-stop-lox-tomato (RTM) animals was performed as previously described (Meletis et al., 2008). Adult animals were given 2 $\mathrm{mg}$ of tamoxifen dissolved in corn oil with $10 \%$ ethanol, once a day for $5 \mathrm{~d}$ to induce recombination. Tamoxifen was allowed to clear out of the animal's system for $10 \mathrm{~d}$ before undergoing SCI.

Statistics. Data were analyzed in Prism (GraphPad Software) for statistical significance using one- or two-way ANOVAs with post hoc $t$ tests corrected for multiple comparisons with Bonferroni's correction.

\section{Results}

\section{AAV-shPTEN knocks down PTEN in vitro and in vivo}

In designing our shRNA tool, we took advantage of an shRNA sequence that has previously been shown to effectively knock down PTEN expression in vitro and in vivo. Luikart et al. (2011) injected a lentiviral vector encoding shPTEN into the dentate gyrus of neonatal and young adult mice and found that the PTEN protein was reduced in virus-infected neurons, resulting in larger neurons and a net increase in excitatory input onto these cells. Because this shRNA sequence was able to knock down PTEN in vivo enough to produce a physiological effect, we cloned this same sequence into in an AAV2 vector containing a U6 promoter to drive shRNA expression and a CMV-driven GFP reporter (AAV-shPTEN-GFP). We then validated our construct similar to what was done by Luikart et al. (2011). We transduced HEK cells with AAV-shPTEN-GFP or AAV-GFP (as a control) for $3 \mathrm{~d}$ and compared PTEN and phospho-S6 levels via Western blot. Phospho-S6 was used as a readout of the MTOR pathway activation, which is increased after PTEN deletion (Park et al., 2008; Liu et al., 2010). We found that PTEN levels were reduced by $58 \%$ and phospho-S6 levels were increased 3.2-fold after AAVshPTEN infection compared with controls (Fig. 1E). Considering that not all cells are infected with AAVs, these results suggest an efficient suppression of PTEN expression in these cells.

To assess the effects of our AAV constructs in the mouse cortex in vivo, we injected AAV-shPTEN-GFP $(n=3)$ or AAV-GFP $(n=3)$ into the cortex of wild-type mice at neonatal ages. These mice were raised to the age of 7 weeks and subjected to a full crush SCI at the spinal cord level T8. At $1 \mathrm{~d}$ after injury, the mice were 

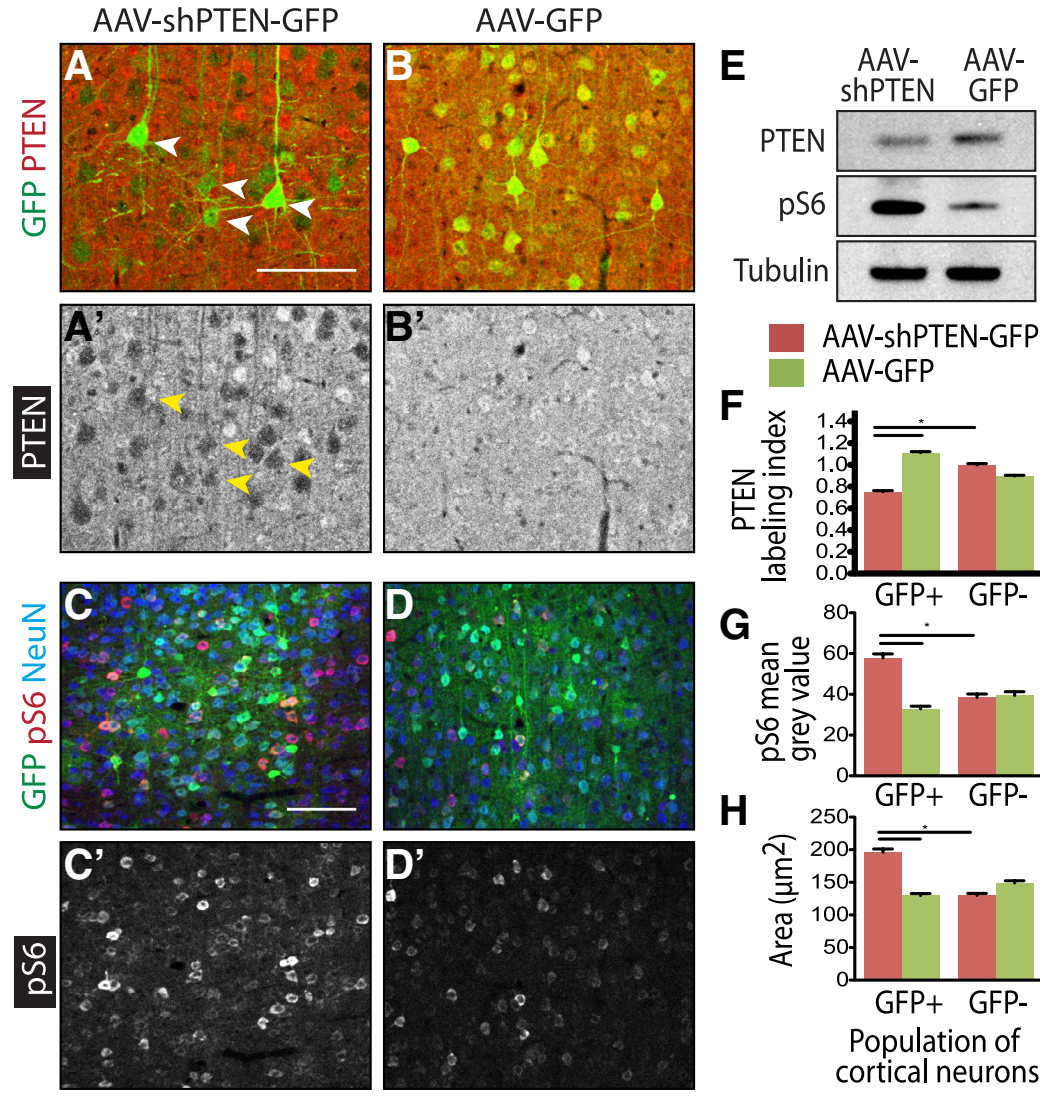

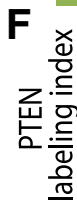

AAV-GFP
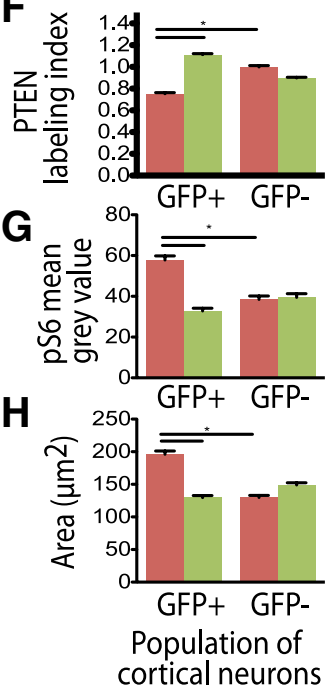

Figure 1. AAV-shPTEN knocks down PTEN in vitro and in vivo. $\boldsymbol{A}-\boldsymbol{D}$, Representative sagittal sections of layer 5 cortex immunostained with antibodies against GFP (green), NeuN (blue, $\boldsymbol{C}, \boldsymbol{D})$, and PTEN (red, $\boldsymbol{A}, \boldsymbol{B})$ or phospho-S6 (pS6, red, $\boldsymbol{C}, \boldsymbol{D})$ ). PTEN $\left(\boldsymbol{A}^{\prime}, \boldsymbol{B}^{\prime}\right)$ or pS6 $\left(\boldsymbol{C}^{\prime}, \boldsymbol{D}^{\prime}\right)$ channels alone in white. (Pixel values in $\boldsymbol{A}^{\prime}, \boldsymbol{B}^{\prime}$ are not inverted.) $\boldsymbol{A}, \boldsymbol{A}^{\prime}, \boldsymbol{C}, \boldsymbol{C}^{\prime}$, From animals injected with AAV-shPTENGFP. $\boldsymbol{B}, \boldsymbol{B}^{\prime}, \boldsymbol{D}, \boldsymbol{D}^{\prime}$, From animals injected with AAV-GFP. $\boldsymbol{A}, \boldsymbol{A}^{\prime}$, Arrows indicate GFP ${ }^{+}$neurons that have decreased PTEN levels. Scale bar, $100 \mu \mathrm{m}$. $\boldsymbol{E}$, Western blots of lysates of HEK cells transduced with AAV-shPTEN-GFP or AAV-GFP, stained with antibodies against PTEN, pS6, or tubulin (loading control). $\boldsymbol{F}-\boldsymbol{H}$, Quantification of PTEN labeling index (F), pS6 mean gray value $(\boldsymbol{G})$, and area $(\boldsymbol{H})$ of $\mathrm{GFP}^{+}$versus $\mathrm{GFP}^{-}$cortical neurons. Error bars indicate SEM. ${ }^{*} p<0.05$.

cortex of neonatal mice, raised the mice to 7 weeks of age, performed a full crush SCI at T8, injected the axon tracer BDA into the right cortex 6 weeks later, and perfused the mice 8 weeks after SCI. Sagittal sections through the lesion site for 9 of 11 surviving shPTEN animals and 7 of 7 surviving GFP animals (4 died) were stained for BDA to analyze axon regeneration. GFAP immunoreactivity was used to visualize the lesion, and Hoechst 33342 was used to visualize cellular nuclei. As shown in Figure 2, representative images from one control and two different shPTEN animals demonstrate that, whereas there is very little regeneration in controls, there is robust CST axon regeneration through and beyond the lesion in the shPTEN animals (Fig. $2 A-C, A^{\prime}-C^{\prime}$ ). The number of regenerating axons at different distances beyond the lesion was quantified, and the amount of regeneration at $0,100,500$, and $1000 \mu \mathrm{m}$ from the caudal edge of the lesion was statistically different in shPTEN versus control animals (Fig. 2D).

In an independent experiment, we repeated this procedure with another 6 shPTEN and 5 control animals, but with the T8 crush injury occurring at 8 weeks of age, instead of 7 weeks. Similar results were obtained (Fig. 2E). Together, these results are consistent with the notion that shRNA-mediated PTEN suppression, like PTEN gene deletion, is also able to activate the intrinsic regenerative ability and response of CST axons after injury. terminated for immunohistochemical analysis. Adjacent sagittal sections were stained with the neuronal marker NeuN, the virus infection marker GFP, and PTEN or phospho-S6. PTEN staining is practically uniform on control AAV-GFP-infected brains (Fig. $\left.1 B, B^{\prime}\right)$, similar to what was shown by Luikart et al. (2011). However, PTEN immunoreactivity is dramatically reduced in the virusinfected, GFP-positive cortical neurons (Fig. 1 $A, A^{\prime}$ ). The darker areas of the image indicate a reduction of PTEN levels. The phospho-S6 levels, on the other hand, are increased in shPTENinfected neurons compared with controls (Fig. $1 C, C^{\prime}, D, D^{\prime}$ ). Quantification of GFP-positive versus GFP-negative neurons indicated that PTEN levels are lower and phospho-S6 levels are higher in GFP-positive neurons from shPTEN brains compared with controls (Fig. $1 F, G$ ), whereas these levels are not significantly different in GFP-negative neurons in shPTEN versus control brains. Furthermore, GFP-positive neurons from shPTEN brains are also larger than those in control brains (Fig. $1 H$ ), consistent with previous results (Liu et al., 2010; Luikart et al., 2011). Thus, these results indicate that the AAV-shPTEN virus is able to effectively knock down PTEN and activate the mTOR pathway in cortical neurons in vivo.

\section{AAV-shPTEN activates CST axon regeneration}

To determine whether AAV-shPTEN is sufficient to activate the intrinsic growth of CST axons, we injected AAV-shPTEN-GFP $(n=11)$ or AAV-GFP $(n=11)$ into the right somatosensory

\section{Regenerating axons are not spared axons}

The observed regenerating axons are unlikely to be spared axons for the following reasons. First, we chose to use a full crush injury that would reliably severe all CST axons instead of a partial injury, such as a dorsal column or contusion injury, that would knowingly leave some CST axons intact. Second, our experimental design included a negative control group, which consistently had few to no axons beyond the lesion (Fig. $\left.2 A, A^{\prime}, D, E\right)$. If our injury method were sparing axons, we would expect to see them in control as well as experimental animals. Third, given that spared axons would be expected to be seen farther from the lesion than $1.5-2 \mathrm{~mm}$, we analyzed cross sections of the spinal cord $5 \mathrm{~mm}$ caudal to the lesion for every animal and never detected BDA-labeled axons at that level (Fig. 3C). To ensure that spared axons could be seen at that level if they existed, we injected BDA into the cortex of uninjured animals and collected sections from a level equivalent to $5 \mathrm{~mm}$ caudal to the lesion $(\sim \mathrm{T} 11)$. Indeed, there are many BDA-labeled axons at T11 when all axons are "spared" (Fig. 3C). Finally, we analyzed spinal cords from shPTEN animals at earlier time points $(n=3$ for each) and found a time-dependent change, with no axons beyond the lesion at 2 weeks after injury and axons just beginning to grow beyond the lesion at 3 and 4 weeks after injury (Fig. $3 D, E$ ). If axons beyond the lesion were spared, their appearance would be expected to be the same at early and late time points. 

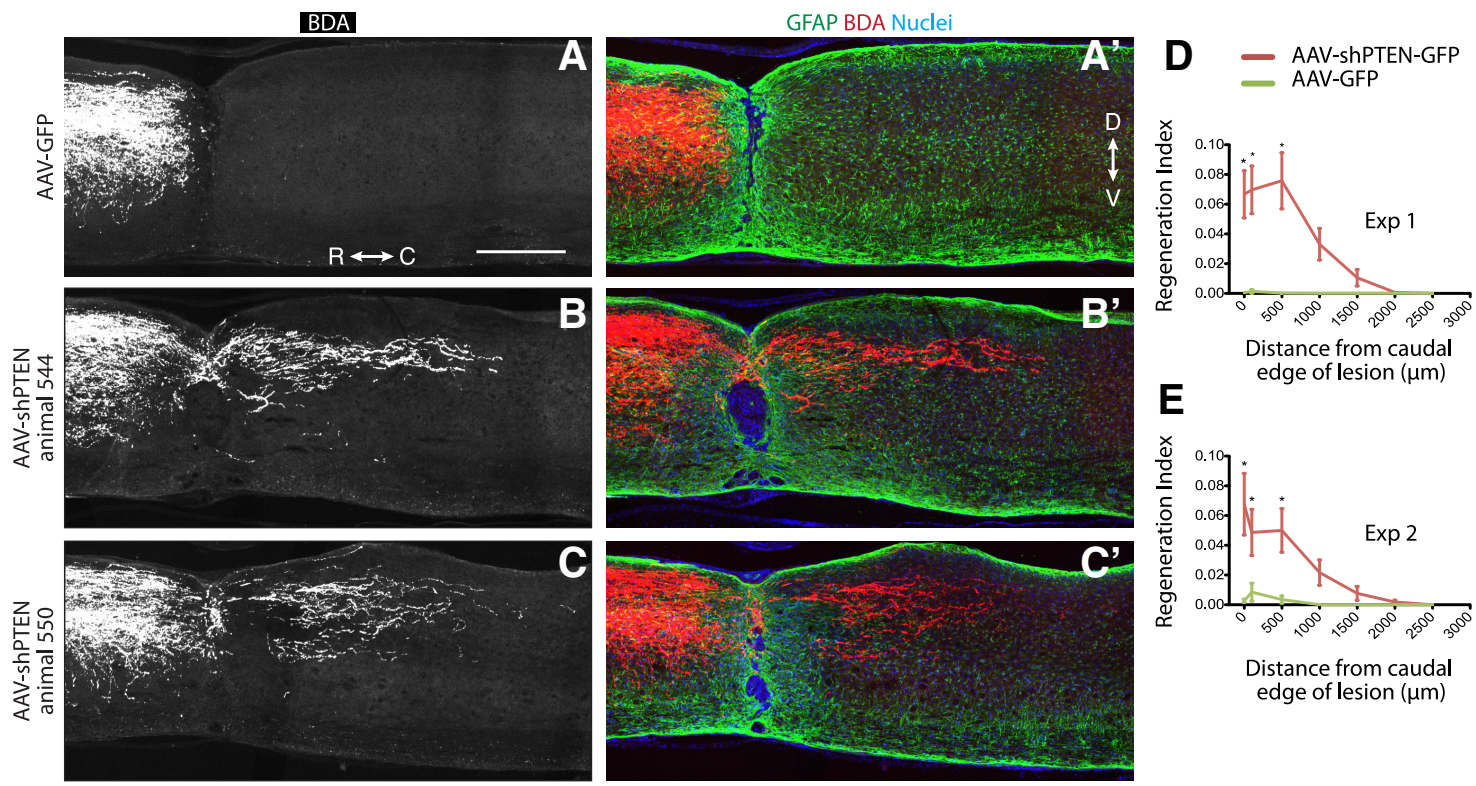

Figure 2. AAV-shPTEN activates CST axon regeneration. $A-C$, Representative sagittal sections of the SCI site at 8 weeks after injury. BDA-labeled CST axons are shown as follows: $A-C$, white; $A^{\prime}-C^{\prime}$, red. $A^{\prime}-C^{\prime}$, Green represents GFAP immunostaining; blue represents nuclei. $A$, From an AAV-GFP animal. $B$, C, From two different AAV-shPTEN animals. R, Rostral; $C$, caudal; D, dorsal; $V$, ventral. Scale bar, $500 \mu \mathrm{m} . \boldsymbol{D}, \boldsymbol{E}$, Quantification of axon regeneration at various distances from the caudal edge of the lesion normalized to the number of axons labeled in the brainstem pyramidal tract for Experiments (Exp) 1 (D) and $2(\boldsymbol{E}){ }^{*} p<0.05$. Error bars indicate SEM.

In addition, analysis of axons beyond the lesion 8 weeks after injury also suggests that they are not spared. Serial section analysis of every animal reveals that axons seen beyond the lesion are axons that have actually regrown through the lesion. One such series of every fourth section from an shPTEN animal is shown in Figure $3 A$. From this, one can appreciate that there is an extent to the axon growth and that it tapers off after $1.5-2 \mathrm{~mm}$ from the lesion. Spared axons would be expected to continue for longer distances and not taper off so quickly. When axons from each section are traced and aligned to form a $3 \mathrm{D}$ reconstruction, it is evident that axons grow through the lesion and not around it as would be expected from spared axons (Fig. $3 B$ ).

\section{Axons regenerate across the lesion in association with astrocyte bridges}

To begin to understand how PTEN-suppressed axons regrow across a lesion that is known to be inhibitory, we were interested in assessing whether there were certain cell types that appear to support axon growth. Consistent with previous observations (Liu et al., 2010), we noticed that regenerating axons in the lesion tend to colocalize with GFAP ${ }^{+}$cells (Fig. $4 A, A^{\prime}$ ). We therefore systematically analyzed what proportion of axons in the lesion colocalize with $\mathrm{GFAP}^{+}$processes for a representative selection of 7 shPTEN animals. Although only $42 \%$ of the lesion is GFAP ${ }^{+}$, $80 \%$ of the axons in the lesion are in the $\mathrm{GFAP}^{+}$portion (Fig. $4 C, D)$. Moreover, most of the axons that do not colocalize with GFAP are at least near GFAP ${ }^{+}$processes (Fig. $4 A^{\prime}$ ).

Because the animals we analyzed above were terminated at 8 weeks after injury when axons had already crossed the lesion, we then repeated this analysis in another set of the animals at 4 weeks after injury, a stage in which regenerating axons are actually crossing the lesion (Fig. $3 D, E$ ). Indeed, at 4 weeks after injury, $26 \%$ of the lesion is $\mathrm{GFAP}^{+}$, whereas $73 \%$ of axons in the lesion are in the $\mathrm{GFAP}^{+}$portion $(n=3, p<0.05$; Fig. $\left.4 B, B^{\prime}, C, D\right)$. This suggests that these endogenous GFAP ${ }^{+}$ astrocytes may serve as an important permissive bridge for axon growth across the lesion.
Further, to determine whether such bridges might be required for axon regrowth from PTEN-suppressed axons, we created lesions in shPTEN animals that have very few $\mathrm{GFAP}^{+}$bridges. Instead of crushing the spinal cord with very fine forceps ( $0.1 \mathrm{~mm}$ width), we used wider forceps $(0.5 \mathrm{~mm}$ width) to create a larger lesion (Fig. $5 A, B)$. Such lesions have, proportionately, approximately onefourth the $\mathrm{GFAP}^{+}$bridges as the thinner lesion (Fig. 5C). Remarkably, no PTEN-suppressed axons grew across the wide lesions having few GFAP ${ }^{+}$bridges $(n=4$, Fig. $5 A, D)$. This is consistent with the notion that such bridge-forming astrocytes may be important for the regeneration of PTEN-suppressed axons across the lesion.

\section{$\mathrm{GFAP}^{+}$bridge-forming astrocytes are not derived from ependymal stem cell progeny}

Given that astrocytes are thought be inhibitory for axon regeneration after injury, we were surprised to see that they might play a supportive role for PTEN-suppressed axons. It is known, however, that immature astrocytes are quite permissive for axon growth (Smith et al., 1990; White and Jakeman, 2008; Filous et al., 2010). We then wondered whether there might be two populations of astrocytes in the lesion environment: reactive, scarforming astrocytes derived from mature astrocytes and supportive, immature astrocytes that are newly born from local neural stem cells. To test this, we used a Nestin-CreERT driver line that has previously been shown to specifically label a population of ependymal cells, within which nearly all of the neural stem cell potential of the adult spinal cord lies (Meletis et al., 2008). We crossed this with a lox-stop-lox tomato reporter line (RTM), gave the mice tamoxifen before injury to label local neural stem cells, waited $10 \mathrm{~d}$ to clear out the tamoxifen, performed a T8 crush SCI, and analyzed the lesion site at 4.5 weeks after injury $(n=2)$. Similar to what was previously reported (Meletis et al., 2008; Barnabe-Heider et al., 2010), the ependymal cells around the central canal in the spinal cord were efficiently labeled (Fig. 6A). However, very few of the $\mathrm{GFAP}^{+}$cells in the lesion are RTMpositive as shown in representative sagittal sections: one through the midline containing the central canal (Fig. 6A, $A^{\prime}$ ) and one 

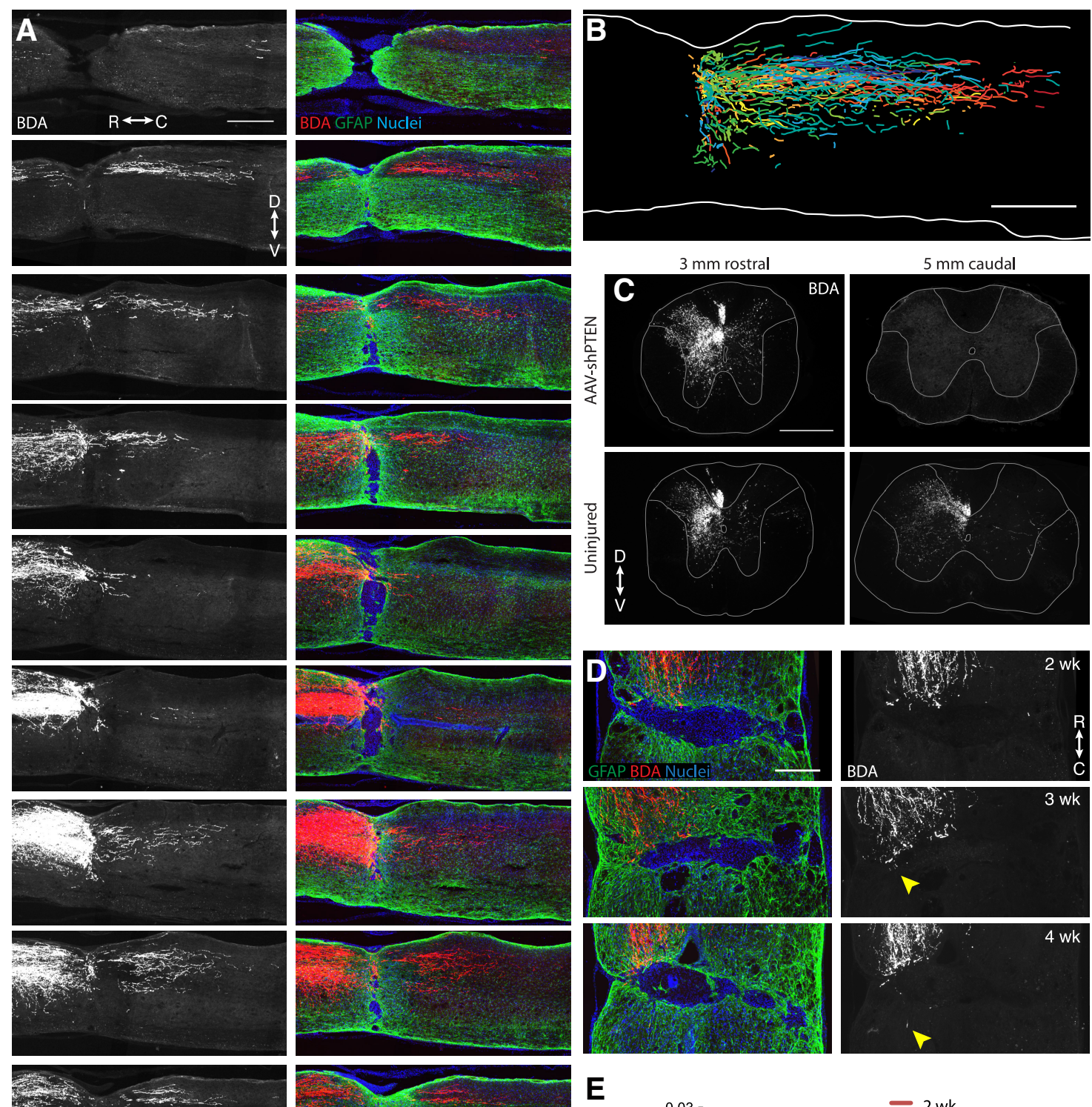

E
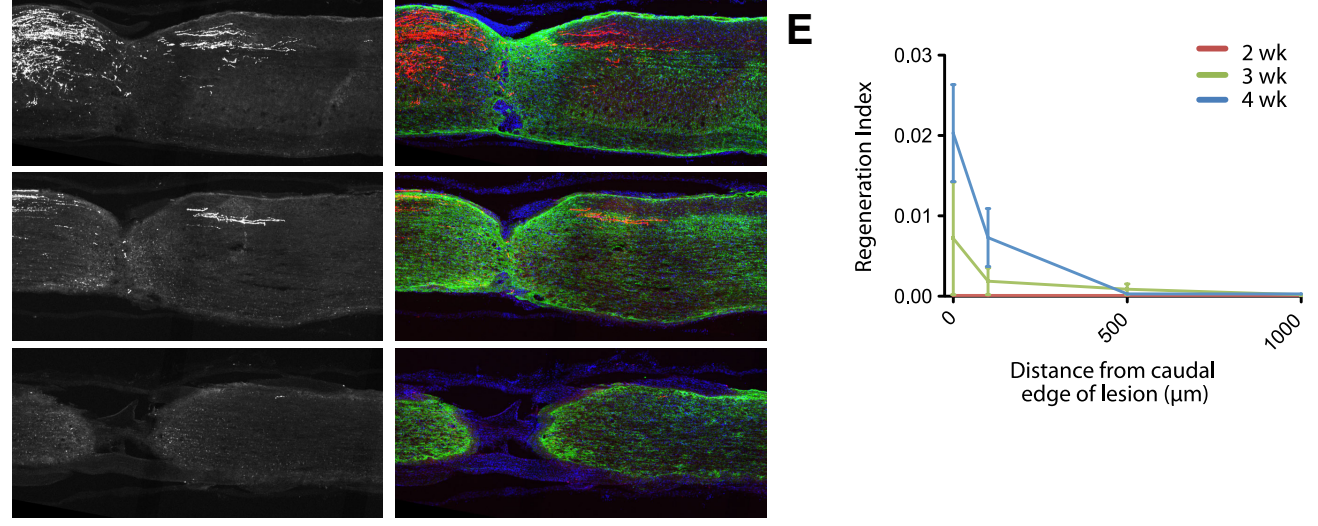

Figure 3. Regenerating axons are not spared axons. A, Serial sagittal sections through the lesion of AAV-shPTEN animal 550, stained for CST axons (BDA, white in single-channel images/red in color-merged images), GFAP (green), and nuclei (blue). $\boldsymbol{B}$, Tracings of CST axons from $\boldsymbol{A}$ overlaid on top of each other to show that axons grow through the middle of the lesion and taper off after $\sim 2 \mathrm{~mm}$. Color represents the left-right position of the axons. C, Cross sections of the spinal cord $3 \mathrm{~mm}$ rostral and $5 \mathrm{~mm}$ caudal to the lesion site (T8) of an AAV-shPTEN animal and an uninjured control, stained for CST axons (BDA).D, Sagittal sections through the lesion of AAV-shPTEN animals at 2, 3, and 4 weeks after injury, stained for CST axons (BDA, white in single-channel images/red in color-merged images), GFAP (green), and nuclei (blue). Arrows indicate axons at the edge of and beyond the lesion at 3 and 4 weeks, respectively. $\boldsymbol{E}$, Quantification of axon regeneration at various distances from the distal edge of the lesion normalized to the number of axons labeled in the brainstem pyramidal tract for AAV-shPTEN-injected animals perfused at 2,3, and 4 weeks after injury. Error bars indicateSEM. R, Rostral; C, caudal; D, dorsal;, , ventral. Scale bars: A-C, 500 $\mu \mathrm{m} ; \mathbf{D}, 250 \mu \mathrm{m}$.

more laterally (Fig. $6 B, B^{\prime}$ ). This suggests that the $\mathrm{GFAP}^{+}$bridgeforming cells we observed in our spinal cord crush injury model are not primarily formed by progeny of these local stem cells but instead are likely derived from mature astrocytes. Considering recent evidence for the heterogeneity of astrocytes (White et al., 2010; Tsai et al., 2012; Zamanian et al., 2012), it is possible that these $\mathrm{GFAP}^{+}$bridge-forming cells may represent a subset of astrocytes in the spinal cord. 

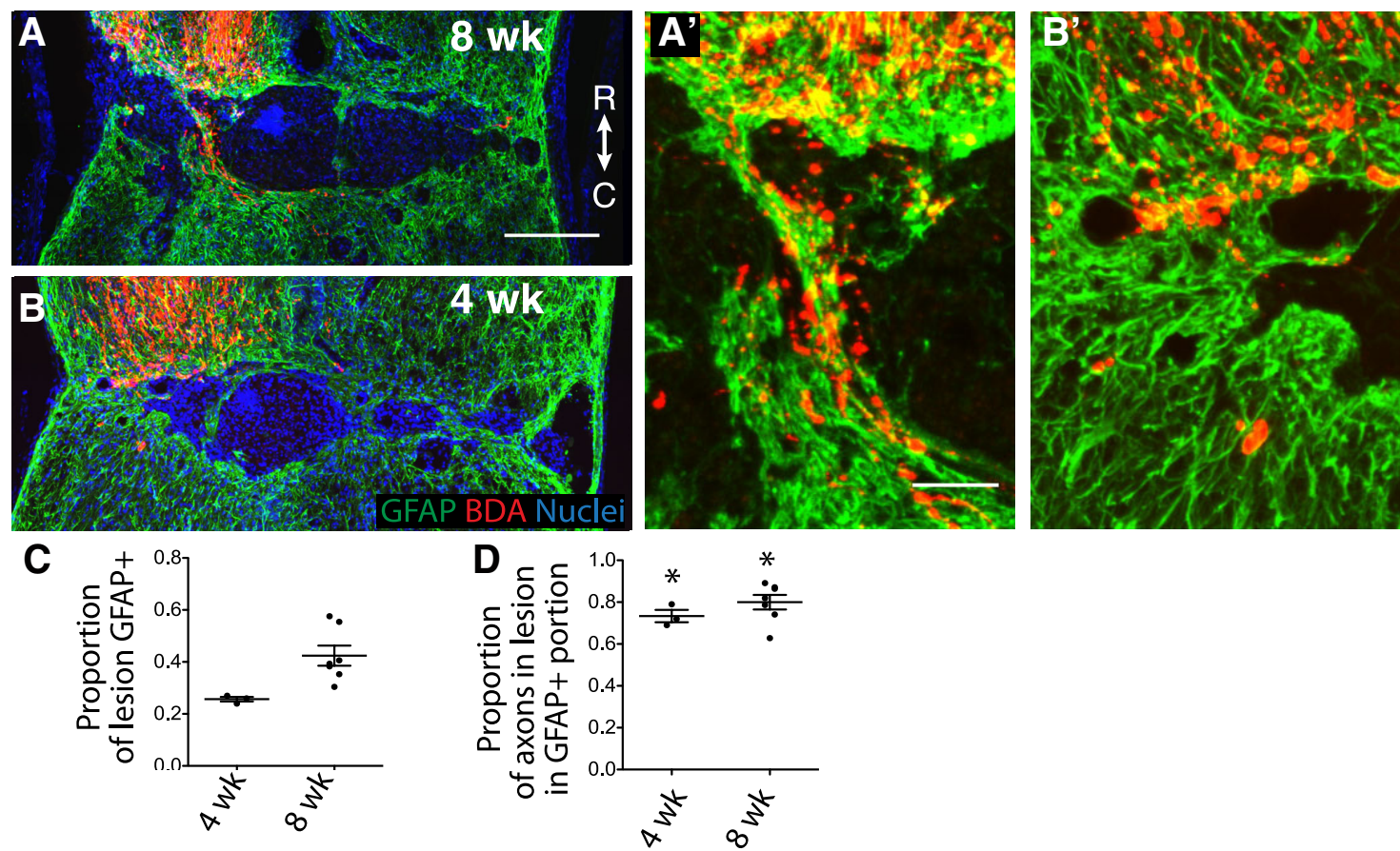

Figure 4. Axons grow across the lesion in association with GFAP ${ }^{+}$astrocyte bridges. $\boldsymbol{A}, \boldsymbol{B}$, Representative sagittal sections through the lesion of AAV-shPTEN animals at $8(\boldsymbol{A})$ and $4(\boldsymbol{B})$ weeks after injury, stained for (ST axons (BDA, red), GFAP (green), and nuclei (blue). $\boldsymbol{A}^{\prime}, \boldsymbol{B}^{\prime}$, Close-ups of axons crossing the lesion in association with GFAP ${ }^{+}$bridges (without the nuclei staining). $\boldsymbol{C}, \boldsymbol{D}$, The proportion of the lesion that is $\mathrm{GFAP}^{+}(\boldsymbol{C})$ and the proportion of axons in the lesion that are in the GFAP ${ }^{+}$portion of the lesion $(\boldsymbol{D})$ at 4 and 8 weeks after injury. ${ }^{*} p<0.05$, the mean is different from the mean proportion of the lesion that is GFAP ${ }^{+}$, thus indicating that regenerating axons have a preference for the GFAP ${ }^{+}$bridges. Dot plots with bars indicating mean \pm SEM. R, Rostral; $C$, caudal. Scale bars: $\boldsymbol{A}, \boldsymbol{B}, 200 \mu \mathrm{m} ; \boldsymbol{A}^{\prime}, \boldsymbol{B}^{\prime}, 50 \mu \mathrm{m}$.

\section{Fibroblasts and macrophages are in the lesion areas axons avoid}

With our model of enhanced intrinsic axon growth, we have the unique opportunity to analyze what cell types might be inhibitory, even to PTEN-suppressed axons. For axons that do regenerate through the lesion, they tend to avoid areas of the lesion containing compact spheres of cells. Using fibronectin as a marker for fibroblasts $(n=3)$ and ibal as a marker for macrophages $(n=3)$, we found that these cell types were present in the areas of the lesion axons avoided (Fig. $7 A, A^{\prime}, B, B^{\prime}$ ). For axons that did not grow through the lesion, they tended to stop at the edge of the lesion that is well defined by fibronectin expression (compare Fig. $7 A, A^{\prime}$ ). Again, to test whether the same is true at a time when axons are actively crossing the lesion, we analyzed animals terminated at 4 weeks after injury and observed similar results ( $n=3$ for each; Fig. $\left.7 C, C^{\prime}, D, D^{\prime}\right)$.

In both sets of samples, fibroblasts and non-bridge-forming astrocytes appear to form a sharp boundary at the edge of the lesion that may represent a physical barrier that blocks the regeneration of PTEN-suppressed axons. On the other hand, although the majority of macrophages occupy the dense areas of the lesion site, which regenerating axons avoid, some are also present in areas surrounding the lesion (Fig. $7 B, B^{\prime}, D, D^{\prime}$ ). However, it is unknown whether these represent different populations of macrophages. These results suggest the possibility that fibroblasts and macrophages may play a role in inhibiting axon growth.

\section{Regenerated axons are able to form synapses}

We next examined several important parameters for the ability of regenerating axons to form functional connections. Specifically, we determined whether axons beyond the lesion grow toward their physiological targets, form synaptic structures, and become myelinated. For this, we analyzed two shPTEN animals in cross section and found that the majority of axons beyond the lesion are located in the left dorsal horn of the spinal cord (Fig. $8 A-D$ ). Comparing this with the normal projection pattern of CST fibers in the mouse spinal cord (Figs. $8 \mathrm{H}$ and $3 \mathrm{C}$ ), it appears that regenerating fibers grow in the vicinity of their normal targets. This pattern was consistent for both animals analyzed in this way (see also Fig. $8 E, G$ ), suggesting that these regenerating axons are able to reach their physiological target areas. Similar to intact CST axons in the gray matter (Fig. $8 \mathrm{H}, \mathrm{H}^{\prime}$ ), these regenerating axons are not myelinated (Fig. $8 G^{\prime}$ ).

We also determined whether regenerating axons reform synaptic structures. To do this, we stained adjacent sections with antibodies against the presynaptic marker Vglut1 and the neuronal marker NeuN or the postsynaptic marker postsynaptic density protein 95 (PSD95). Similar to what was seen after PTEN gene deletion (Liu et al., 2010), many BDA-labeled axons beyond the lesion colocalize with Vglut1 (Fig. $8 E^{\prime}$ ), and some of these BDA-positive Vlgut1-positive structures can be seen to form around neurons (Fig. $8 E^{\prime \prime}$ ) and are in close opposition to PSD95 ${ }^{+}$ boutons (Fig. $8 F-F^{\prime \prime}$ ). Although the identity of their postsynaptic partners is unknown, these results indicated that regenerating axons are capable of forming synapses. Together, BDA-labeled regenerating axons appear to grow toward appropriate targets and form synaptic structures, suggesting that these axons might be able to reconnect with their physiological targets after injury.

\section{Discussion}

In this study, we show that an shRNA-assisted approach can successfully be used to knock down PTEN expression and activate intrinsic axon growth after SCI. These results nicely recapitulate those seen with PTEN gene deletion in our previous studies (Liu 

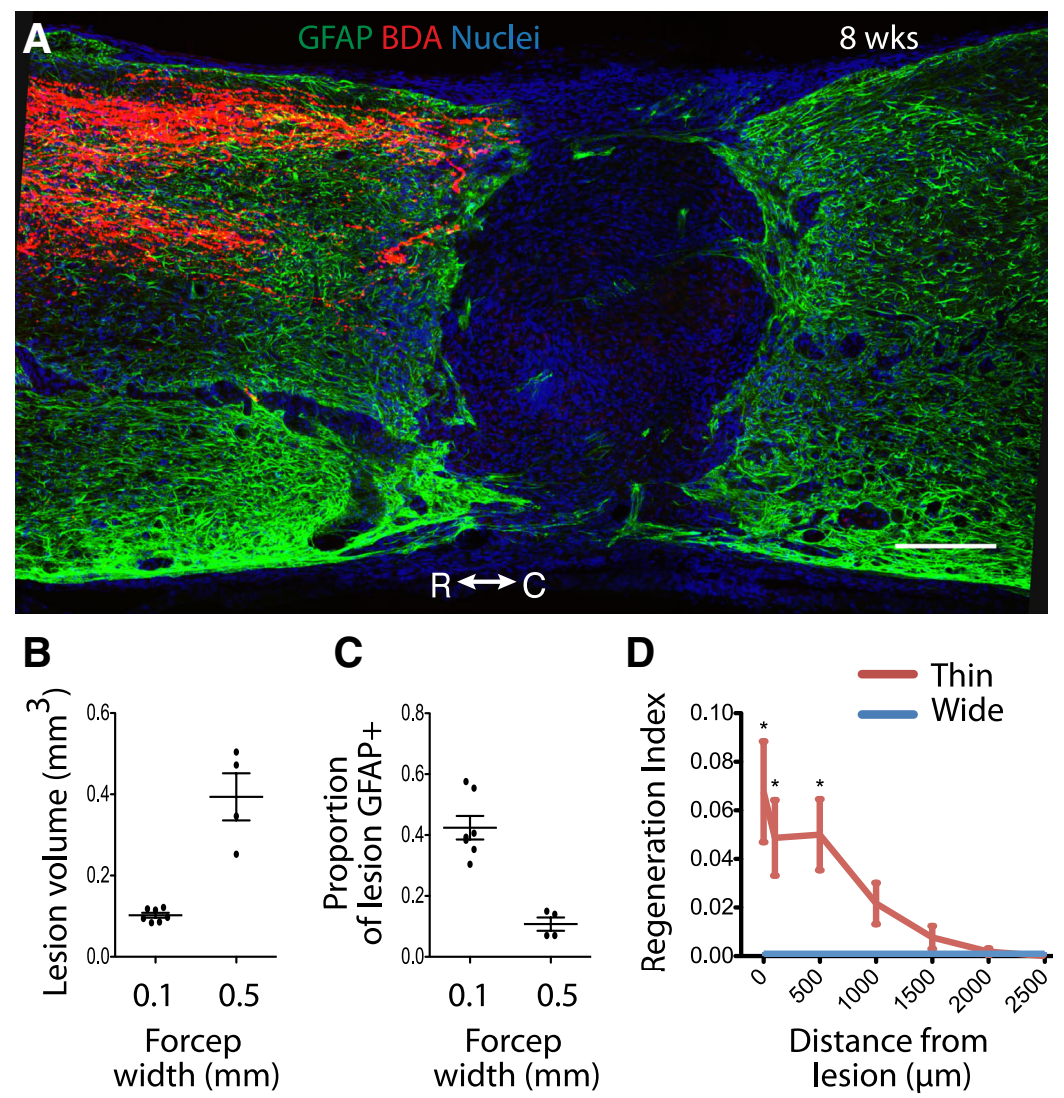

Figure 5. PTEN-suppressed axons do not cross the lesion if the lesion is large. $A, A$ representative sagittal section through the lesion of an AAV-shPTEN animal injured with forceps that are $0.5 \mathrm{~mm}$ wide instead of $0.1 \mathrm{~mm}$. Red represents (ST axons (BDA); green represents GFAP; blue represents nuclei. $\boldsymbol{B}-\boldsymbol{D}$, Quantification of the lesion volume $(\boldsymbol{B})$, proportion of the lesion that is GFAP ${ }^{+}$ $(\boldsymbol{C})$, and axon regeneration $(\boldsymbol{D})$ from animals injured with wide $(0.5 \mathrm{~mm})$ versus thin $(0.1 \mathrm{~mm})$ forceps. Dot plots with bars indicating mean \pm SEM. R, Rostral; C, caudal. Scale bar, $200 \mu \mathrm{m}$.

et al., 2010). With both methods of PTEN depletion, extensive axon regeneration, up to $2 \mathrm{~mm}$ beyond the lesion, is achieved 8 weeks after SCI. Because RNA interference methods often only partially suppress the expression of target genes, as opposed to the complete suppression obtained by genetic deletion, our data suggest that other nongenetic strategies, such as small-molecule inhibitors, might also have the potential to stimulate CST regeneration. In addition, we found that the regenerating axons resulting from PTEN knockdown grow in the vicinity of their normal targets in the dorsal horn and also appear to form synapses in the spinal cord caudal to the lesion. These data suggest that CST axons that have regenerated beyond the lesion have the potential to transmit brain-derived signals across the lesion. Although we did not observe significant gross behavioral improvements in these animals with the T8 crush injury, it is possible that more sensitive behavioral assays are needed to monitor functional recovery in these animals. In this aspect, it is important to note that the function of the CST in hindlimb function in mice is not well characterized. In addition, our future studies will focus on optimizing the conditions for efficiently introducing AAV-shRNAs into the adult cortex to analyze their effects in chronic injury settings.

With this shRNA strategy to promote the intrinsic regenerative ability of CST axons, we are more poised to revisit the role of extrinsic regulators of axon regeneration. Because injured axons typically cannot regrow in the adult CNS, many previous studies have had to rely on in vitro assays with cultured embryonic neurons to study the cellular and molecular nature of inhibitory environments. This makes it difficult to know what is really preventing growth and what could be important for providing a permissive pathway for adult neurons in vivo.

Analyses of the lesion site in our model of enhanced axon growth suggest that $\mathrm{GFAP}^{+}$astrocytes might play an important role in allowing axons to grow across the lesion. This is largely based on the observation that axons regenerating in the lesion predominantly colocalize with $\mathrm{GFAP}^{+}$processes, despite the existence of many other cell types. This is also supported by the fact that PTEN-suppressed axons do not grow through large lesions that have fewer $\mathrm{GFAP}^{+}$bridges. Interestingly, the $\mathrm{GFAP}^{+}$astrocytes in the lesion appear to have a different phenotype than those forming the glial scar. Instead of having thick, interwoven processes, they appear to have longer processes that run more parallel to each other and the direction axons must travel (Fig. 4). This phenotype is reminiscent of the phenotype adopted by astrocytes in species that are able to regenerate their spinal cords, such as the newt and turtle (Rehermann et al., 2009; Zukor et al., 2011), and thus suggests that the mammalian spinal cord has some competence to respond to an SCI in a way that supports regenerative healing. This phenotype is also similar to that of immature, bipolar astrocytes, which are known to be permissive for axon regeneration (White and Jakeman, 2008; Filous et al., 2010).

This led us to speculate that the bridge-forming astrocytes might, therefore, be derived from local stem cell progeny, whereas the scar-forming astrocytes might be derived from mature astrocytes that have become reactive. Meletis et al. (2008) and Barnabe-Heider et al. (2010) used a Nestin-CreERT line to follow the fate of stem cell progeny after a large dorsal column injury and found many stem cell progeny in the lesion at 1 and 6 months after injury. We obtained this same Nestin-CreERT line, induced recombination the same way as the Frisen group (Meletis et al., 2008; Barnabe-Heider et al., 2010), injured the spinal cord with our T8 full crush method, and found surprisingly few stem cell progeny in the lesion at 1 month after injury. The differences between our results might be the result of differences in the injury model used. Whereas our injury is deliberately fine, leaves the meninges intact, and causes minimal bleeding, their injury cuts the meninges, spans several millimeters, and likely causes more bleeding. Thus, the number and type of infiltrating cells are likely very different, as well as the set of growth factors and cytokines released. It is also unclear how many infiltrating cells might also express the Cre-dependent reporter. Nonetheless, we found that most of the $\mathrm{GFAP}^{+}$processes in our lesions are not derived from stem cells. If these processes represent an immature, permissive type of astrocyte, it suggests that mature astrocytes have the capacity to dedifferentiate to support growth rather than become reactive and form a scar. Recent studies suggest that 

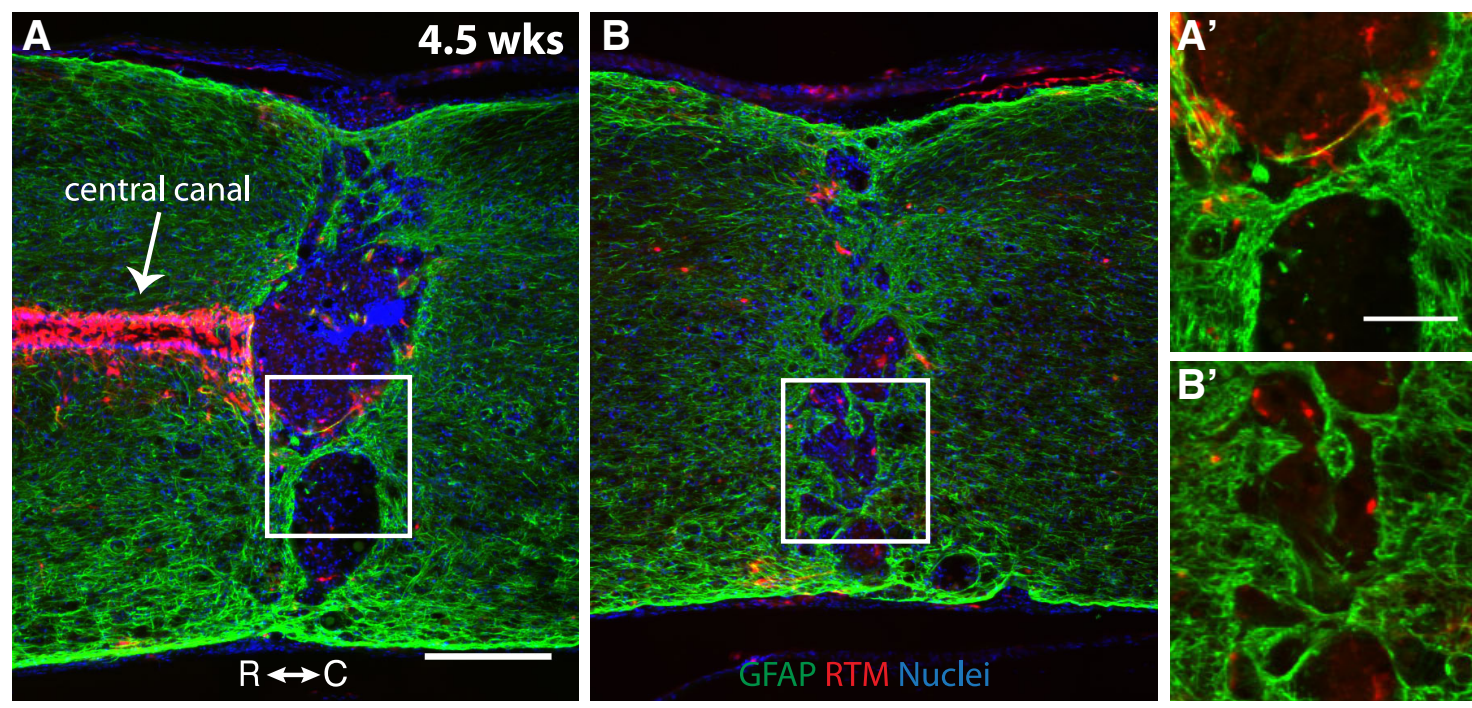

Figure 6. Astrocyte bridges are not formed by stem cell progeny. $\boldsymbol{A}, \boldsymbol{B}$, Representative sagittal sections through the lesion of a Nestin-CreERT, RTM animal at 4.5 weeks after injury, a time when axons are crossing the lesion, stained for the stem cell progeny marker (RTM, red), GFAP (green), and nuclei (blue). $\boldsymbol{A}^{\prime}, \boldsymbol{B}^{\prime}$, Close-ups of the GFAP bridges (boxes in $\left.\boldsymbol{A}, \boldsymbol{B}\right)$ which are not predominantly RTM $^{+}$(nuclear staining omitted). R, Rostral; $C$, caudal. Scale bars: $\boldsymbol{A}, \boldsymbol{B}, 250 \mu \mathrm{m} ; \boldsymbol{A}^{\prime}, \boldsymbol{B}^{\prime}, 100 \mu \mathrm{m}$.

GFAP BDA FN

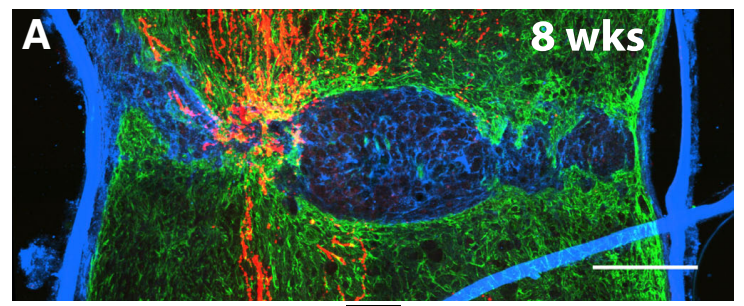

FN

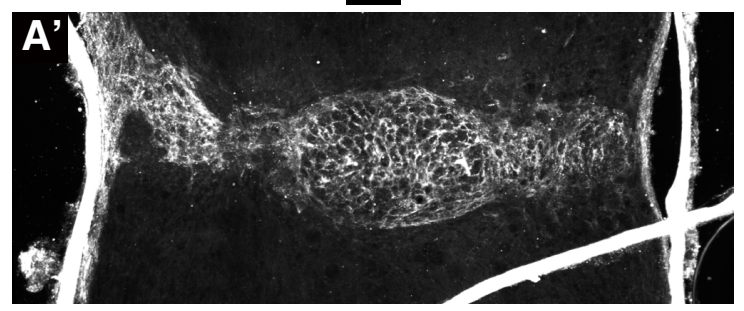

GFAP BDA FN

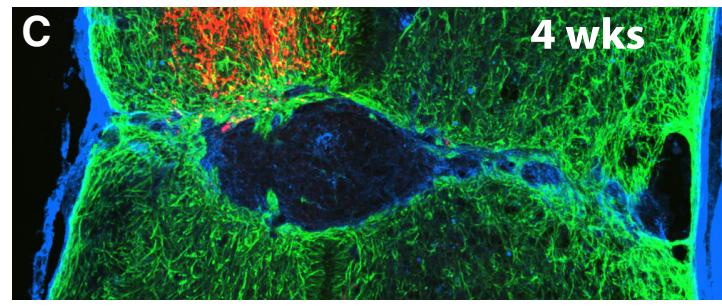

FN

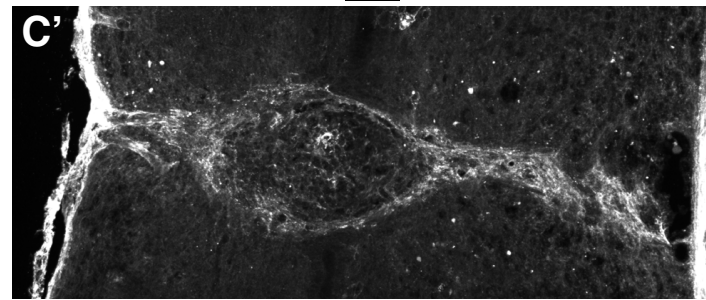

GFAP BDA iba1

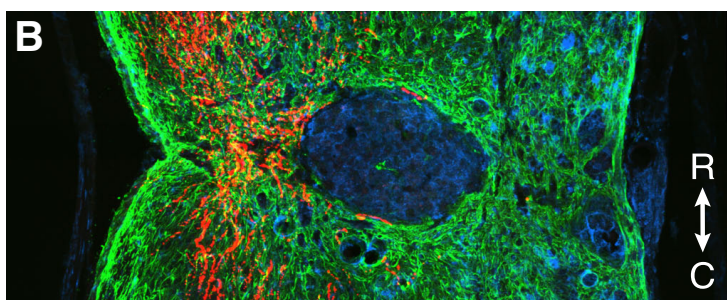

iba1

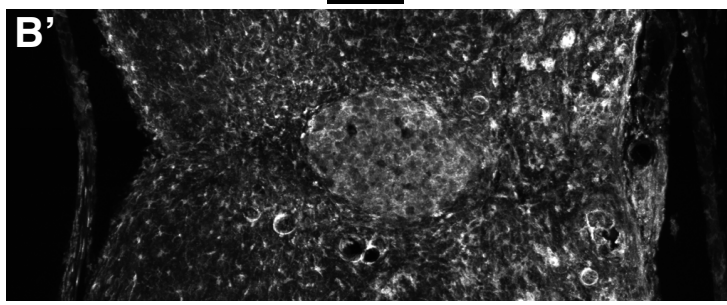

GFAP BDA iba1

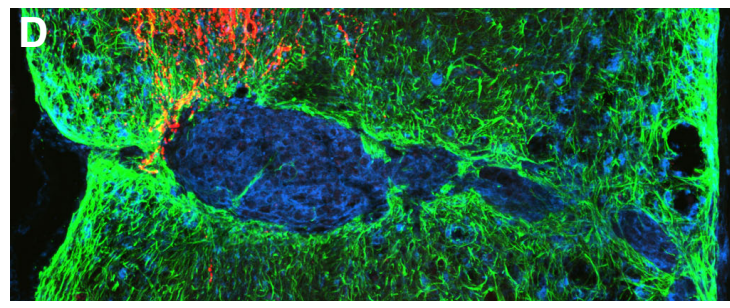

iba1

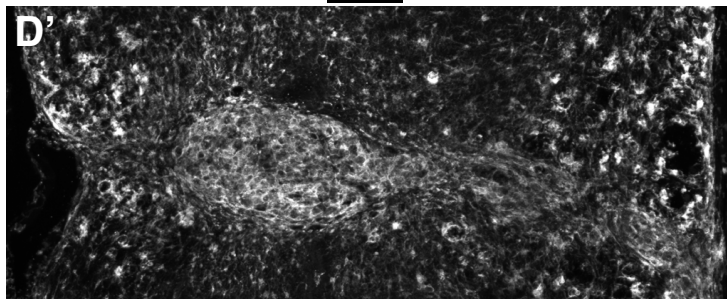

Figure 7. Fibroblasts and macrophages are in areas of the lesion axons avoid. $\boldsymbol{A}-\boldsymbol{D}$, Representative sagittal sections through the lesion of AAV-shPTEN animals at $8(\boldsymbol{A}, \boldsymbol{B})$ and $4(\boldsymbol{C}, \boldsymbol{D})$ weeks after injury, stained for CST axons (BDA, red), GFAP (green), and the fibroblast marker, fibronectin (blue, $A, C$ or the macrophage marker, iba1 (blue, $\boldsymbol{B}, \boldsymbol{D})$. Fibronectin $\left(\boldsymbol{A}^{\prime}, \boldsymbol{C}^{\prime}\right)$ or iba1 $\left(\boldsymbol{B}^{\prime}, \boldsymbol{D}^{\prime}\right)$ channels alone in white. $R$, Rostral; C, caudal; FN, fibronectin. Scale bar, $200 \mu \mathrm{m}$. 

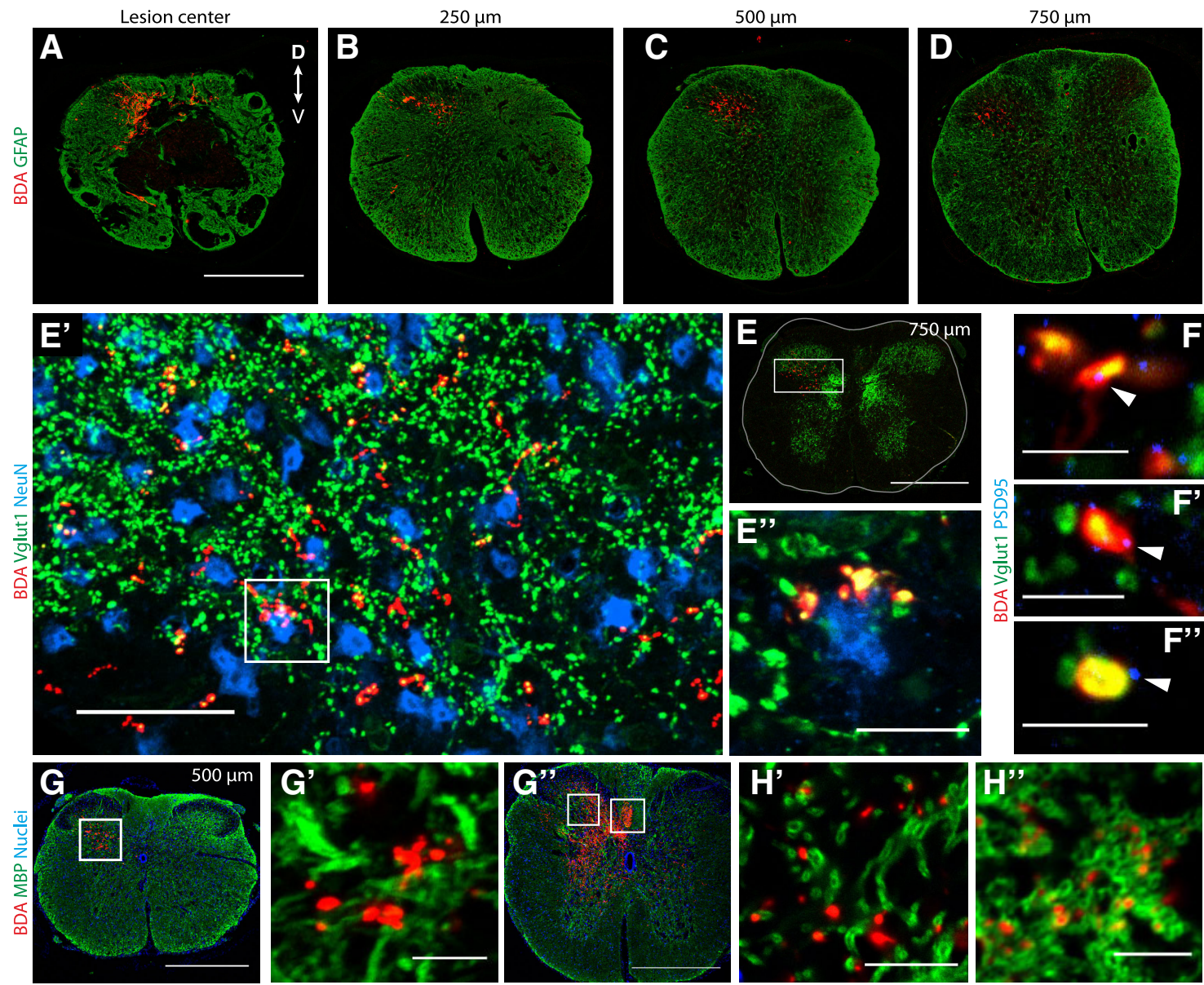

Figure 8. Regenerated axons have functional characteristics. $A-D$, Cross sections of the spinal cord of an AAV-shPTEN animal, 8 weeks after $S C l$, through the lesion center $(\boldsymbol{A})$, and 250 $\mu \mathrm{m}(\boldsymbol{B}), 500 \mu \mathrm{m}(\boldsymbol{C})$, and $750 \mu \mathrm{m}(\boldsymbol{D})$ caudal to the lesion, stained for CST axons (BDA, red) and GFAP (green). Axons appear to regenerate to/in the vicinity of their normal targets (Fig. 3C). $\boldsymbol{E}$, Cross section of another AAV-shPTEN animal at 8 weeks after $S \mathrm{Cl}$, at $750 \mu \mathrm{m}$ caudal to the lesion, stained for (ST axons (BDA, red), the presynaptic marker Vglut 1 (green), and the neuronal marker NeuN (blue, shown only in $\left.\boldsymbol{E}^{\prime}, \boldsymbol{E}^{\prime \prime}\right)$. $\boldsymbol{E}^{\prime}$, Enlargement of box in $\boldsymbol{E}$ showing many Vlgut1 ${ }^{+}$BDA-labeled axons. $\boldsymbol{E}^{\prime \prime}$, Enlargement of box in $\boldsymbol{E}^{\prime}$ showing several Vglut1 ${ }^{+}$BDA ${ }^{+}$ terminals around a neuron. $\boldsymbol{F}-\boldsymbol{F}^{\prime \prime}$, Adjacent section from the animal in $\boldsymbol{E}$, at $750 \mu \mathrm{m}$ from the lesion, stained for (ST axons (BDA, red), Vglut1 (green), and the postsynaptic marker PSD95 (blue) showing three examples of Vglut ${ }^{+}$BDA-labeled axons in close opposition to PSD95 ${ }^{+}$boutons (arrows). $\mathbf{G}$, Adjacent section from the animal in $\boldsymbol{E}$, at $500 \mu \mathrm{m}$ from the lesion, stained for CST axons (BDA, red), myelin basic protein (green), and nuclei. $\boldsymbol{G}^{\prime}$, Enlargement of box in $\boldsymbol{G}$ showing BDA ${ }^{+}$axons does not appear to be myelinated. $\boldsymbol{H}$, Cross section of "intact" spinal cord $3 \mathrm{~mm}$ rostral to the lesion, stained as in $\boldsymbol{G}$. $\boldsymbol{H}^{\prime}$, Enlargement of left box in $\boldsymbol{H}$ showing that BDA-labeled CST axons are not normally myelinated in the gray matter. $\boldsymbol{H}^{\prime \prime}$, Enlargement of right box in $\mathbf{G}$ showing that CST axons are myelinated in the white matter (main CST bundle in dorsal column). D, Dorsal; V, ventral. Scale bars: $\boldsymbol{A}-\mathbf{G}, 500 \mu \mathrm{m} ; \boldsymbol{E}^{\prime}, 50 \mu \mathrm{m}$; $E^{\prime \prime}, G^{\prime}, H^{\prime}, 10 \mu \mathrm{m} ; \boldsymbol{F}-\boldsymbol{F}^{\prime \prime}, \boldsymbol{H}^{\prime \prime}, 5 \mu \mathrm{m}$.

region-specific astrocytes might have different developmental origins (Tsai et al., 2012). Even astrocyte-reactive gliosis is a highly heterogeneous state in which astrocyte activities are altered to respond to the specific injury (Zamanian et al., 2012). Understanding the identity of these bridge-forming astrocytes and what drives these divergent responses will give insights into how to create more astrocyte bridges for axon regeneration.

In addition to identifying permissive cell types, our PTEN suppression/deletion model of activating intrinsic growth also allows us to assess what is inhibitory for axon regeneration. Although some PTEN-suppressed axons do grow through the lesion, many fail to do so. As mentioned above, those that fail stop at the interface between reactive astrocytes and fibroblasts at the lesion border, suggesting that this border may present a barrier for regeneration (Shearer and Fawcett, 2001; Bundesen et al., 2003). Axons that do grow through the lesion completely avoid dense clumps of cells that are often present in the lesion core. These areas contain large numbers of fibroblasts and macrophages, suggesting that such structures are inhibitory for axon growth. Consistent with this idea, it has been shown that macrophages might contribute to axonal dieback after injury (Horn et al., 2008; Busch et al., 2009, 2011). Similarly, several Semaphorins, known axonal repellents, are strongly expressed by fibroblasts in the injury site (Pasterkamp and Verhaagen, 2006).

Despite these facts, this does not necessarily mean that fibroblasts and macrophages are always inhibitory. In particular, some macrophages can be found dispersed in the region where axons are growing beyond the lesion. It is unknown whether these macrophages might represent the "alternatively activated" antiinflammatory (M2) macrophages previously described as being present in the core of a mouse SCI lesion at early time points after injury or whether they represent "classically activated" proinflammatory (M1) macrophages that are dispersed enough to allow axon growth to occur (Kigerl et al., 2009). In any case, our observations suggest that such tight clumps of fibroblasts and macrophages may be repelling both axons and perhaps astrocytes. It is possible that astrocytes and axons are found together in the lesion because they are both independently 
finding the more permissive regions of the fibrotic scar. In vitro data, however, support the idea that axons prefer to grow on astrocytes versus fibroblasts and that astrocytes and fibroblasts segregate into exclusive domains (Ness and David, 1997; Shearer and Fawcett, 2001; Bundesen et al., 2003). Learning what might break up this segregation, this tight cluster of fibroblasts and macrophages in the fibrotic scar, to allow more astrocytes to bridge the injury, will likely improve axon regeneration across the lesion.

In conclusion, both Cre-assisted PTEN gene deletion and shRNA-mediated PTEN protein suppression are able to activate the intrinsic growth of CST axons after SCI and enable many axons with functional characteristics to regrow beyond the lesion. Even with this, inhibitory factors in the lesion are still capable of inhibiting the projection of such activated axons. Many CST axons do not grow into the lesion after a thin T8 crush, and none of them grows through a wide T8 crush. Thus, combining the PTEN suppression/deletion method of activating intrinsic growth with those aimed at modifying the lesion environment has great promise in improving axon regeneration. Our studies suggest that strategies that increase the formation of astrocyte bridges and/or break up the dense cluster of fibroblasts and macrophages in the lesion core are strong candidates for such combinatorial approaches. Our new shRNA tool will now allow us to use cell-specific Cre drivers to alter cellular responses and test the ability of the manipulation to improve axon regeneration. It will also allow us to translate findings into other mammalian models for which targeted mutations are not possible.

\section{References}

Afshari FT, Kappagantula S, Fawcett JW (2009) Extrinsic and intrinsic factors controlling axonal regeneration after spinal cord injury. Expert Rev Mol Med 11:e37. CrossRef Medline

Barnabé-Heider F, Göritz C, Sabelström H, Takebayashi H, Pfrieger FW, Meletis K, Frisén J (2010) Origin of new glial cells in intact and injured adult spinal cord. Cell Stem Cell 7:470-482. CrossRef Medline

Blackmore MG, Wang Z, Lerch JK, Motti D, Zhang YP, Shields CB, Lee JK, Goldberg JL, Lemmon VP, Bixby JL (2012) Kruppel-like Factor 7 engineered for transcriptional activation promotes axon regeneration in the adult corticospinal tract. Proc Natl Acad Sci U S A 109:75177522. CrossRef Medline

Bundesen LQ, Scheel TA, Bregman BS, Kromer LF (2003) Ephrin-B2 and $\mathrm{EphB} 2$ regulation of astrocyte-meningeal fibroblast interactions in response to spinal cord lesions in adult rats. J Neurosci 23:77897800. Medline

Busch SA, Horn KP, Silver DJ, Silver J (2009) Overcoming macrophagemediated axonal dieback following CNS injury. J Neurosci 29:99679976. CrossRef Medline

Busch SA, Hamilton JA, Horn KP, Cuascut FX, Cutrone R, Lehman N, Deans RJ, Ting AE, Mays RW, Silver J (2011) Multipotent adult progenitor cells prevent macrophage-mediated axonal dieback and promote regrowth after spinal cord injury. J Neurosci 31:944-953. CrossRef Medline

Condic ML, Lemons ML (2002) Extracellular matrix in spinal cord regeneration: getting beyond attraction and inhibition. Neuroreport 13:A37A48. CrossRef Medline

Davies JE, Huang C, Proschel C, Noble M, Mayer-Proschel M, Davies SJ (2006) Astrocytes derived from glial-restricted precursors promote spinal cord repair. J Biol 5:7. CrossRef Medline

Davies SJ, Goucher DR, Doller C, Silver J (1999) Robust regeneration of adult sensory axons in degenerating white matter of the adult rat spinal cord. J Neurosci 19:5810-5822. Medline

Filous AR, Miller JH, Coulson-Thomas YM, Horn KP, Alilain WJ, Silver J (2010) Immature astrocytes promote CNS axonal regeneration when combined with chondroitinase ABC. Dev Neurobiol 70:826-841. CrossRef Medline

Grieger JC, Choi VW, Samulski RJ (2006) Production and characterization of adeno-associated viral vectors. Nat Protoc 1:1412-1428. CrossRef Medline

Hammarlund M, Nix P, Hauth L, Jorgensen EM, Bastiani M (2009) Axon regeneration requires a conserved MAP kinase pathway. Science 323:802806. CrossRef Medline

Horn KP, Busch SA, Hawthorne AL, van Rooijen N, Silver J (2008) Another barrier to regeneration in the CNS: activated macrophages induce extensive retraction of dystrophic axons through direct physical interactions. J Neurosci 28:9330-9341. CrossRef Medline

Kigerl KA, Gensel JC, Ankeny DP, Alexander JK, Donnelly DJ, Popovich PG (2009) Identification of two distinct macrophage subsets with divergent effects causing either neurotoxicity or regeneration in the injured mouse spinal cord. J Neurosci 29:13435-13444. CrossRef Medline

Kurimoto T, Yin Y, Omura K, Gilbert HY, Kim D, Cen LP, Moko L, Kügler S, Benowitz LI (2010) Long-distance axon regeneration in the mature optic nerve: contributions of oncomodulin, cAMP, and pten gene deletion. J Neurosci 30:15654-15663. CrossRef Medline

Lee JK, Zheng B (2012) Role of myelin-associated inhibitors in axonal repair after spinal cord injury. Exp Neurol 235:33-42. CrossRef Medline

Liu K, Lu Y, Lee JK, Samara R, Willenberg R, Sears-Kraxberger I, Tedeschi A, Park KK, Jin D, Cai B, Xu B, Connolly L, Steward O, Zheng B, He Z (2010) PTEN deletion enhances the regenerative ability of adult corticospinal neurons. Nat Neurosci 13:1075-1081. CrossRef Medline

Liu K, Tedeschi A, Park KK, He Z (2011) Neuronal intrinsic mechanisms of axon regeneration. Annu Rev Neurosci 34:131-152. CrossRef Medline

Luikart BW, Schnell E, Washburn EK, Bensen AL, Tovar KR, Westbrook GL (2011) Pten knockdown in vivo increases excitatory drive onto dentate granule cells. J Neurosci 31:4345-4354. CrossRef Medline

Maier IC, Schwab ME (2006) Sprouting, regeneration and circuit formation in the injured spinal cord: factors and activity. Philos Trans R Soc Lond B Biol Sci 361:1611-1634. CrossRef Medline

Meletis K, Barnabé-Heider F, Carlén M, Evergren E, Tomilin N, Shupliakov O, Frisén J (2008) Spinal cord injury reveals multilineage differentiation of ependymal cells. PLoS Biol 6:e182. CrossRef Medline

Moore DL, Blackmore MG, Hu Y, Kaestner KH, Bixby JL, Lemmon VP, Goldberg JL (2009) KLF family members regulate intrinsic axon regeneration ability. Science 326:298-301. CrossRef Medline

Ness R, David S (1997) Leptomeningeal cells modulate the neurite growth promoting properties of astrocytes in vitro. Glia 19:47-57. CrossRef Medline

Park KK, Liu K, Hu Y, Smith PD, Wang C, Cai B, Xu B, Connolly L, Kramvis I, Sahin M, He Z (2008) Promoting axon regeneration in the adult CNS by modulation of the PTEN/mTOR pathway. Science 322: 963-966. CrossRef Medline

Pasterkamp RJ, Verhaagen J (2006) Semaphorins in axon regeneration: developmental guidance molecules gone wrong? Philos Trans R Soc Lond B Biol Sci 361:1499-1511. CrossRef Medline

Qiu J, Cai D, Dai H, McAtee M, Hoffman PN, Bregman BS, Filbin MT (2002) Spinal axon regeneration induced by elevation of cyclic AMP. Neuron 34:895-903. CrossRef Medline

Rehermann MI, Marichal N, Russo RE, Trujillo-Cenóz O (2009) Neural reconnection in the transected spinal cord of the freshwater turtle Trachemys dorbignyi. J Comp Neurol 515:197-214. CrossRef Medline

Schneider CA, Rasband WS, Eliceiri KW (2012) NIH Image to ImageJ: 25 years of image analysis. Nat Methods 9:671-675. CrossRef Medline

Shearer MC, Fawcett JW (2001) The astrocyte/meningeal cell interface: a barrier to successful nerve regeneration? Cell Tissue Res 305:267-273. CrossRef Medline

Shin JE, Cho Y, Beirowski B, Milbrandt J, Cavalli V, DiAntonio A (2012) Dual leucine zipper kinase is required for retrograde injury signaling and axonal regeneration. Neuron 74:1015-1022. CrossRef Medline

Silver J, Miller JH (2004) Regeneration beyond the glial scar. Nat Rev Neurosci 5:146-156. CrossRef Medline

Smith GM, Rutishauser U, Silver J, Miller RH (1990) Maturation of astrocytes in vitro alters the extent and molecular basis of neurite outgrowth. Dev Biol 138:377-390. CrossRef Medline

Smith PD, Sun F, Park KK, Cai B, Wang C, Kuwako K, Martinez-Carrasco I, Connolly L, He Z (2009) SOCS3 deletion promotes optic nerve regeneration in vivo. Neuron 64:617-623. CrossRef Medline

Sun F, Park KK, Belin S, Wang D, Lu T, Chen G, Zhang K, Yeung C, Feng G, Yankner BA, He Z (2011) Sustained axon regeneration induced by codeletion of PTEN and SOCS3. Nature 480:372-375. CrossRef Medline 
Tsai HH, Li H, Fuentealba LC, Molofsky AV, Taveira-Marques R, Zhuang H, Tenney A, Murnen AT, Fancy SP, Merkle F, Kessaris N, Alvarez-Buylla A, Richardson WD, Rowitch DH (2012) Regional astrocyte allocation regulates CNS synaptogenesis and repair. Science 337:358-362. CrossRef Medline

Watkins TA, Wang B, Huntwork-Rodriguez S, Yang J, Jiang Z, EasthamAnderson J, Modrusan Z, Kaminker JS, Tessier-Lavigne M, Lewcock JW (2013) DLK initiates a transcriptional program that couples apoptotic and regenerative responses to axonal injury. Proc Natl Acad Sci U S A 110:4039-4044. CrossRef Medline

White RE, Jakeman LB (2008) Don't fence me in: harnessing the beneficial roles of astrocytes for spinal cord repair. Restor Neurol Neurosci 26:197-214. Medline

White RE, McTigue DM, Jakeman LB (2010) Regional heterogeneity in astrocyte responses following contusive spinal cord injury in mice. J Comp Neurol 518:1370-1390. CrossRef Medline

Xin L, Lawson DA, Witte ON (2005) The Sca-1 cell surface marker enriches for a prostate-regenerating cell subpopulation that can initiate prostate tumorigenesis. Proc Natl Acad Sci U S A 102:6942-6947. CrossRef Medline

Yan D, Wu Z, Chisholm AD, Jin Y (2009) The DLK-1 kinase promotes mRNA stability and local translation in C. elegans synapses and axon regeneration. Cell 138:1005-1018. CrossRef Medline

Yiu G, He Z (2006) Glial inhibition of CNS axon regeneration. Nat Rev Neurosci 7:617-627. CrossRef Medline

Zamanian JL, Xu L, Foo LC, Nouri N, Zhou L, Giffard RG, Barres BA (2012) Genomic analysis of reactive astrogliosis. J Neurosci 32:6391-6410. CrossRef Medline

Zolotukhin S, Byrne BJ, Mason E, Zolotukhin I, Potter M, Chesnut K, Summerford C, Samulski RJ, Muzyczka N (1999) Recombinant adenoassociated virus purification using novel methods improves infectious titer and yield. Gene Ther 6:973-985. CrossRef Medline

Zukor KA, Kent DT, Odelberg SJ (2011) Meningeal cells and glia establish a permissive environment for axon regeneration after spinal cord injury in newts. Neural Dev 6:1. CrossRef Medline 